\title{
Association of information, education, and communication; and enrollment in health insurance: A case of Nepal
}

Devaraj Acharya ( $\nabla$ drabmc@gmail.com )

Tribhuvan University https://orcid.org/0000-0003-0847-4836

\section{Bhimsen Devkota}

Tribhuvan University

Kamal Gautam

Tribhuvan University

Radha Bhattarai

Tribhuvan University

Research article

Keywords: Enrollment, health insurance, information, education, communication, Nepal

Posted Date: December 19th, 2019

DOI: https://doi.org/10.21203/rs.2.14369/v2

License: (a) (i) This work is licensed under a Creative Commons Attribution 4.0 International License. Read Full License 


\section{Abstract}

Background

Most of the studies have indicated that various programmes were failing due to lack of appropriate information, education, and communication [IEC] to the target audiences. But still unanswered that which methods or means of communication could be the most powerful for changing behaviour, decision making, and or desired action. The paper aims to assess the effects of IEC on the enrollment of health insurance [HI] in Nepal.

Methods

A cross-sectional study, with randomly selected 810 [ 405 enrolled and 405 not-enrolled] households, was conducted at Baglung and Kailali districts of Nepal in 2018 using pretested structured interview tool. Background characteristics of family and respondents, and exposure to the means of communication were independent variables; and enrollment of $\mathrm{HI}$ was the dependent variable. Univariate, bivariate, and multivariate analyses were done to interpret the data.

Results

Data show that socio-demographics and exposure to $\mathrm{HI}$ related information were associated with the enrollment of HI. Demographic characteristics of the respondents and households particularly age, wealth status, and presence of chronic diseases in the family were significantly associated with the enrollment of HI. Similarly, exposure to communication and media such as heard about $\mathrm{HI}$ and knowledge of contribution amount of $\mathrm{HI}$, having $\mathrm{HI}$ related books or guidelines, participation in training and workshop, discussion with peers and neighbours, exposure to $\mathrm{HI}$ related messages from radio and television, seen hoarding board, newspaper, and $\mathrm{HI}$ related pamphlet, brochure, and posters were significantly associated with enrollment in $\mathrm{HI}$. Heard about $\mathrm{HI}$ and knowledge of contribution amount, having $\mathrm{HI}$ related books and guidelines, and discussion with peers and neighbours appeared to be the positive and significant predictors for enrollment in $\mathrm{HI}$.

Conclusion

Communication and interaction with peers and neighbours about $\mathrm{HI}$ scheme of the government could lead to higher participation in $\mathrm{HI}$ programme. It would be better to incorporate this strategy while planning policies and interventions on $\mathrm{HI}$.

\section{Background}

Government of Nepal [GoN] has made commitment to achieve Universal Health Coverage [UHC] by 2030 which is one of the targets of Sustainable Development Goals [SDGs] for good health and wellbeing [SDG 3] (1). Besides this, the Constitution of Nepal [CoN] has also declared basic health services as one of the fundamental rights of the citizen (2). However, the GoN has allocated less than three percent of its total budget for health sector (3) which is said to be insufficient to meet the targets of global agenda of good health and wellbeing for all and constitutional provision of right to healthcare. Therefore, appropriate and sustainable financing for health is needed to meet the targets and agendas. The GoN has formulated Health Insurance Act [HIA] 2017 to ascertain the financial sustainability for health care $(3,4)$. Health Insurance [HI] programme was initially introduced as Social Health Security [SHS] in 2016 under the provision of Development Board Act 1956 in Kailali, Baglung and Ilam Districts in initial phase (5).

Health Insurance Programme [HIP] is relatively a new programme for Nepalese people. So, it has obviously both opportunity and challenge to implement. An opportunity in the sense of new programme to the households and challenge in the sense that people may or may not participate in the HIP since they may not have adequate and correct information about it. A survey conducted in Kailali District shows that only nine percent people had good knowledge about $\mathrm{HI}$ (6). Department of Health Services shows about only eight percent population were enrolled in HIP as of November, 2018 from 36 districts but less than three [2.4] percent population were enrolled in Baglung and Kailali Districts, and majority did not renewed their scheme $(3,5)$. This may be happening because of inadequate information, education, and communication [IEC] activities. Inadequate IEC leads to poor enrollment, lower retention, and fewer renewal as well.

The HIP in Nepalese context requires proper sensitization and information to the targeted population in mass level. Various interventions such as sensitization, awareness, orientation, and training shall be conducted for mass enrollment $(7,8)$. However, it is still unanswered which method would be more appropriate to get people informed about HIP. Health Insurance Board [HIB] has set 
three tiers of communication strategy at policy level, community level and household level but the strategy is yet to be validated (9). IEC is a combination of strategies, methods and approaches that enables a person to adopt a dynamic role in improving quality of life through healthy conducts (10). IEC is not only limited to the process of changing behaviour but also a process of political, social and economic transformation. Adequate IEC approaches can encourage and support to follow up for positive behaviour change (11). IEC creates awareness, increases knowledge, changes attitude, and moves people towards change and continues their behaviours to adopt new innovation (12). It updates and upgrades knowledge, awareness and attitudes for favourable change in behaviour or decision making $(13,14)$.

Nepal Demographic and Health Survey [NDHS] 2016 shows that more than half [50 and 51\%] of young adults [15-49 years] had access to Television. They watched Television at least once a week, 27.7 percent of women and 36.1 percent of men had access to Radio and listened at least once a week, and 37.2 percent of women and 31 percent of men had no access to Newspaper, Television or Radio at least once a week. However, 24 percent women and 50 percent men had access to internet and they used it within past 12 months (15). Nearly half of the population had no access of mass media which may prevent them from accessing health related information including health insurance. NDHS 2016 further indicates that Television was the most common media and half of the people had access upon it (15).

Good and healthy behaviours are often time consuming, costly, difficult, inconvenient, complicated and even less rewarded. Therefore, people generally do not follow the healthy behaviour (16). Rather it leads to negative attitude towards health behaviours. So, it needs appropriate intervention to overcome the negative attitude. A bad IEC could damage individuals' wellbeing but a good IEC could lead to change positively in their behaviour and lives (17). Gathering all people in the main stream of IEC is a difficult task. It does not only change the behaviour but develops culture and civilization. It is a process of transforming innovations, ideas, opinions and new trends (18).

IEC informs, inspires, motivates, enables, and empowers people for making decision towards the healthy way by making changes in terms of knowledge, attitudes, and beliefs (19). Communication is a power for decision making for behaviour change. It makes individuals positive, motivating, encouraging, and supportive for understanding (20). IEC consists several methods, approaches, and interventions but it is neither evaluated nor assessed which method and approach would be better for behaviour change in relation to enrollment in health insurance in the context of Nepal. So the article aims to assess the association of information, education, and communication on enrollment in health insurance.

\section{Methods}

\section{Research approach and design}

The study used cross-sectional survey design and household was the unit of study. Mainly quantitative data were collected and analysed accordingly.

\section{Study field/area}

The study was undertaken in Baglung and Kailali Districts of Nepal. Baglung is located at hill in mid-western part and Kailali is situated in Terai and south-western part of Nepal. HIB initiated HIP at these districts in initial phase (3).

\section{Population and sample}

All households residing in Baglung and Kailali Districts were the population of the study. There were two types of sample: enrolled and non-enrolled. The required sample size was calculated by using online SurveyMonkey software (21), where population size according to latest National Household Census was 204,002 [61,522 and 142,480 households in Baglung and Kailali respectively] (22), confidence level 95 percent and five percent margin of error. It showed estimate sample size of 385 [in round figure] that was equal to the sample size of Daniel's formula $(23,24)$.

By adjusting the non-response rate of five percent as experienced at NDHS 2016 (15), the sample reached 405 for enrolled family and the same size was determined for non-enrolled household. Sample for enrolled household accounted 122 for Baglung and 283 for 
Kailali as per population proportion as per latest household census survey 2011 (22). List of households was obtained from HIB district offices and household unit was randomly selected for enrolled sample. There were 9779 households were enrolled by midJanuary, 2018. The proximal household of enrolled household, which was not enrolled in HIP, was selected as non-enrolled sample, random sampling was used if more than one household in the proximity.

\section{Data collection tool}

Interview schedule [IS]was used for research tool. It was pretested and modified for validation prior to administration. The IS was validated by test-retest method which had eight sections. The Cronbach's alpha was calculated for the validation of attitude statements. But only the results of IEC related section has been presented in this article.

\section{Data collection procedure}

After completing all administrative procedure: ethical approval was received from Nepal Health Research Council [NHRC], obtained permission from HIB central and district offices, we intended to collect data from household head [HH]. If $\mathrm{HH}$ was absent or did not respond, then another senior member of the household or another nearest household was selected. Informed consent was taken prior to interview. Data were collected from respondents' house or the place where they felt comfort to respond. Information were collected since March $20^{\text {th }}, 2018$ and it took 75 days to complete.

\section{Data analyses}

Data were cleaned, edited, inspected for accuracy and consistency. There were mostly categorical type of independent and dependent variables. The dependent variable was dichotomous character. Family and individual characters, socio-demographic characters, and IEC related variables were independent variables whereas enrollment of $\mathrm{HI}$ was the dependent variable. Some attributes of variables were lumped due to small frequency. Univariate [frequencies and percentage], bivariate [chi-square test], and multivariate [binary logistic regression] analyses were performed to interpret the data. We used IBM SPSS Statistics 20 to analyse the data.

\section{Ethical consideration}

NHRC reviewed and approved the study proposal on $15^{\text {th }}$ Feb, 2018. We followed National Ethical Guidelines for Health Research in Nepal and Standard Operating Procedure (25) and Ethical Compliance Checklist prepared by American Psychological Association (26) throughout the research process.

\section{Results}

\section{Characteristics of respondents and households}

Of the total 810 respondents, 70 and 30 percent were from Kailali and Baglung respectively. They were drawn as per the proportional distribution of sample based on the national population and household census 2011 (27). Out of them, more than one fourth [26\%] were from rural area. More than half of the respondents [51\%] were female. Among them, two third [66\%] were the household heads. More than 92 percent were literate, more than half of them had basic and secondary level of education, and 12 percent had bachelor or higher level of education. Forty-one percent household belonged to nuclear family. Fifty-six percent of the total households had upto five members in the family, 42 percent households had six to 10 members and nearly two percent had more than 10 members in the family. Different nine types of household assets and dwelling were assessed to categorize wealth status in three equal class. So, the wealth status of the people comprised one third each of the rich, middle and poor households.

More than half [51\%] of the total respondents could feed their family throughout the year; 16,14 and 11 percent could feed their family upto three months, three to six months, and six to nine months respectively. Similarly, eight percent of them could feed their family nine to 12 months. More than one third [34.6\%] of the respondents expressed that minimum one family member had some type of chronic 
disease. Half of the respondent were enrolled and half other were not-enrolled in the HIP which was already determined during sample size calculation and sample selection. Seventy-two percent of the respondents expressed that they had some knowledge about health insurance and the remaining 28 percent did not have.

Most of the respondents [71\%] were informed by the enrollment assistant. Nearly half [49\%] of them were informed by Radio/FM, 40 percent from neighbours/peers, 37 percent from Television, 15 percent from family members, 14 percent from female community health volunteers [FCHV] and 11 percent from teachers and Health workers respectively. Nearly two third [66\%] of the respondents had knowledge about contribution amount for $\mathrm{HI}$. Seventeen percent of them had $\mathrm{HI}$ related books or guidelines. However, only five percent had participated in training and discussion related to $\mathrm{HI}$. 
Table 1: Background characteristics of households and respondents $(n=810)$

\begin{tabular}{|c|c|c|c|}
\hline \multirow[t]{2}{*}{ Variables } & \multirow[t]{2}{*}{ Category } & \multicolumn{2}{|c|}{ Total } \\
\hline & & $\%$ & $\mathrm{~N}$ \\
\hline \multirow[t]{2}{*}{ District } & Baglung & 30.1 & 244 \\
\hline & Kailali & 69.9 & 566 \\
\hline \multirow[t]{2}{*}{ Residence type } & Urban & 74.1 & 600 \\
\hline & Rural & 25.9 & 210 \\
\hline \multirow[t]{2}{*}{ Sex of respondents } & Male & 49.0 & 397 \\
\hline & Female & 51.0 & 413 \\
\hline \multirow{2}{*}{ Household head } & No & 34.1 & 276 \\
\hline & Yes & 65.9 & 534 \\
\hline \multirow[t]{2}{*}{ Age group of } & Upto 20 years & 2.8 & 23 \\
\hline & 21 to 40 years & 59.5 & 482 \\
\hline \multirow[t]{2}{*}{ respondents } & 41 to 60 years & 28.8 & 233 \\
\hline & More than 60 years & 8.9 & 72 \\
\hline \multirow[t]{5}{*}{ Educational status } & Illiterate & 7.4 & 60 \\
\hline & Literate & 30.4 & 246 \\
\hline & Basic education & 26.4 & 214 \\
\hline & Secondary education & 24.3 & 197 \\
\hline & Bachelor or above & 11.5 & 93 \\
\hline \multirow[t]{2}{*}{ Type of family } & Nuclear & 41.0 & 332 \\
\hline & Joint & 59.0 & 478 \\
\hline \multirow[t]{3}{*}{ Size of family } & Upto 5 members & 56.4 & 457 \\
\hline & 6 to 10 members & 42.0 & 340 \\
\hline & More than 10 members & 1.6 & 13 \\
\hline \multirow{3}{*}{ Wealth status } & Poor & 33.3 & 270 \\
\hline & Middle & 33.3 & 270 \\
\hline & Rich & 33.3 & 270 \\
\hline \multirow[t]{2}{*}{ Ability to feed the family throughout the year } & No & 48.8 & 395 \\
\hline & Yes & 51.2 & 415 \\
\hline \multirow[t]{2}{*}{ Family member having chronic diseases } & No & 65.4 & 530 \\
\hline & Yes & 34.6 & 280 \\
\hline \multirow[t]{2}{*}{ Enrolled in health insurance } & No & 50.0 & 405 \\
\hline & Yes & 50.0 & 405 \\
\hline \multirow[t]{2}{*}{ Heard about health insurance } & No & 28.0 & 227 \\
\hline & Yes & 72.0 & 583 \\
\hline Sources of information^ & Neighbour/Peer & 40.3 & 235 \\
\hline & Radio/FM & 49.4 & 288 \\
\hline$(n=583)$ & Television & 36.5 & 213 \\
\hline & Family members & 14.8 & 86 \\
\hline & Health worker/Doctor & 11.1 & 65 \\
\hline & Teacher & 11.3 & 66 \\
\hline & FCHV & 13.7 & 80 \\
\hline & Training/seminar & 4.1 & 24 \\
\hline & Enrollment assistant & 70.8 & 413 \\
\hline & Print media and others & 3.8 & 22 \\
\hline Knowledge about contribution amount & No & 34.3 & 278 \\
\hline & Yes & 65.7 & 532 \\
\hline Having $\mathrm{HI}$ related books & No & 83.2 & 674 \\
\hline & Yes & 16.8 & 136 \\
\hline Participated in $\mathrm{HI}$ related training & No & 95.1 & 770 \\
\hline & Yes & 4.9 & 40 \\
\hline Interaction with peers or neighbours about $\mathrm{HI}$ & No & 68.0 & 551 \\
\hline & Yes & 32.0 & 259 \\
\hline Known from social media & No & 80.9 & 655 \\
\hline & Yes & 19.1 & 155 \\
\hline Listened $\mathrm{HI}$ related information from Radio/FM & No & 52.3 & 424 \\
\hline & Yes & 47.7 & 386 \\
\hline Watched $\mathrm{HI}$ related information in TV & No & 61.7 & 500 \\
\hline & Yes & 38.3 & 310 \\
\hline Seen hoarding board & No & 73.3 & 594 \\
\hline
\end{tabular}




\begin{tabular}{llll} 
& Yes & 26.7 & 216 \\
\hline Read newspaper & No & 86.9 & 704 \\
\cline { 2 - 4 } & Yes & 13.1 & 106 \\
\hline Seen brochure/poster/pamphlet & No & 82.5 & 668 \\
\cline { 2 - 4 } & Yes & 17.5 & 142 \\
\hline
\end{tabular}

${ }^{\wedge}$ Multiple responses

Nearly one third [32\%] of the respondents had discussed with peers or neighbours about $\mathrm{HI}$ whereas 19 percent of them were informed through social media. Nearly half of the total respondents listened $\mathrm{HI}$ related messages from Radio whereas 38 percent of them watched $\mathrm{HI}$ related messages from Television. Data show that 27 percent of the respondents saw $\mathrm{HI}$ related message on Hoarding Board and 13 percent read $\mathrm{HI}$ related message from newspapers. Eighteen percent of the respondents received $\mathrm{HI}$ related information from brochure, poster, pamphlet, and flyers.

\section{Family and respondents' characters; information, education, and communication; and enrollment in health insurance}

Out of the total respondents, 50 percent resided in urban area and 49 percent of rural were enrolled. Fifty-three percent of the male respondents were enrolled in $\mathrm{HI}$ compare to 47 percent of female were enrolled. Fifty-three percent of the respondents who were the household heads, were enrolled in $\mathrm{HI}$ compared to 45 percent of those who were not household head [ $p<0.05]$. Data show that higher the age higher the enrollment rate. Twenty-six percent of the respondents of age less than 20 years were enrolled in $\mathrm{HI}$ compared to 44 percent from the age of 21 to 40 years, 59 percent from the age of 41 to 60 years, and 68 percent from the age of more than 60 years $[p<0.001]$. There were no significant differences between educational level of respondents, types of family, and size of family; and enrollment in $\mathrm{HI}$. More than half (56\%) of respondents having rich wealth status were enrolled compared to 46 percent of middle and 49 percent poor wealth status $[p<0.05]$. 
Table 2: Family characteristics and $\mathrm{HI}$ related information, and enrollment in $\mathrm{HI}$

\begin{tabular}{|c|c|c|c|c|c|c|c|}
\hline \multirow{3}{*}{ Variables } & \multirow{3}{*}{ Category } & \multicolumn{4}{|c|}{ Enrolled in health insurance } & \multirow{3}{*}{ Chi Square } & \multirow{3}{*}{$P$ Value } \\
\hline & & \multicolumn{2}{|c|}{ No } & \multicolumn{2}{|c|}{ Yes } & & \\
\hline & & $\mathrm{N}$ & $\%$ & $\mathrm{~N}$ & $\%$ & & \\
\hline \multirow[t]{2}{*}{ District } & Baglung & 122 & 50.0 & 122 & 50.0 & & \\
\hline & Kailali & 283 & 50.0 & 283 & 50.0 & & \\
\hline \multirow[t]{2}{*}{ Residence type } & Urban & 298 & 49.7 & 302 & 50.3 & 0.103 & 0.748 \\
\hline & Rural & 107 & 51.0 & 103 & 49.0 & & \\
\hline \multirow[t]{2}{*}{ Sex of respondents } & Male & 186 & 46.9 & 211 & 53.1 & 3.088 & 0.079 \\
\hline & Female & 219 & 53.0 & 194 & 47.0 & & \\
\hline \multirow[t]{2}{*}{ Household head } & No & 153 & 55.4 & 123 & 44.6 & 4.946 & 0.026 \\
\hline & Yes & 252 & 47.2 & 282 & 52.8 & & \\
\hline \multirow[t]{4}{*}{ Age group of respondents } & Upto 20 years & 17 & 73.9 & 6 & 26.1 & 29.565 & $<0.001$ \\
\hline & 21 to 40 years & 270 & 56.0 & 212 & 44.0 & & \\
\hline & 41 to 60 years & 95 & 40.8 & 138 & 59.2 & & \\
\hline & More than 60 years & 23 & 31.9 & 49 & 68.1 & & \\
\hline \multirow{5}{*}{ Educational status } & Illiterate & 27 & 45.0 & 33 & 55.0 & 2.490 & 0.646 \\
\hline & Literate & 132 & 53.7 & 114 & 46.3 & & \\
\hline & Basic education & 103 & 48.1 & 111 & 51.9 & & \\
\hline & Secondary education & 99 & 50.3 & 98 & 49.7 & & \\
\hline & Bachelor or above & 44 & 47.3 & 49 & 52.7 & & \\
\hline \multirow[t]{2}{*}{ Type of family } & Nuclear & 169 & 50.9 & 163 & 49.1 & 0.184 & 0.668 \\
\hline & Joint & 236 & 49.4 & 242 & 50.6 & & \\
\hline \multirow[t]{3}{*}{ Size of family } & Upto 5 members & 231 & 50.5 & 226 & 49.5 & 0.935 & 0.626 \\
\hline & 6 to 10 members & 166 & 48.8 & 174 & 51.2 & & \\
\hline & More than 10 members & 8 & 61.5 & 5 & 38.5 & & \\
\hline Wealth status & Poor & 139 & 51.5 & 131 & 48.5 & 6.163 & 0.046 \\
\hline & Middle & 147 & 54.4 & 123 & 45.6 & & \\
\hline & Rich & 119 & 44.1 & 151 & 55.9 & & \\
\hline Ability to feed the family throughout the year & No & 197 & 49.9 & 198 & 50.1 & 0.005 & 0.944 \\
\hline & Yes & 208 & 50.1 & 207 & 49.9 & & \\
\hline Family member having chronic diseases & No & 292 & 55.1 & 238 & 44.9 & 15.913 & $<0.001$ \\
\hline & Yes & 113 & 40.4 & 167 & 59.6 & & \\
\hline Heard about health insurance & No & 217 & 95.6 & 10 & 4.4 & 262.260 & $<0.001$ \\
\hline & Yes & 188 & 32.2 & 395 & 67.8 & & \\
\hline Sources of HI related information^ & Neighbour/Peer & 74 & 31.5 & 161 & 68.5 & 102.328 & $<0.001$ \\
\hline & Radio/FM & 101 & 35.1 & 187 & 64.9 & & \\
\hline$(n=583)$ & Television & 68 & 31.9 & 145 & 68.1 & & \\
\hline & Family members & 17 & 19.8 & 69 & 80.2 & & \\
\hline & Health worker/Doctor & 17 & 26.2 & 48 & 73.8 & & \\
\hline & Teacher & 17 & 25.8 & 49 & 74.2 & & \\
\hline & FCHV & 19 & 23.8 & 61 & 76.3 & & \\
\hline & Training/seminar & 6 & 25.0 & 18 & 75.0 & & \\
\hline & Enrollment assistant & 86 & 20.8 & 327 & 79.2 & & \\
\hline & Print media and others & 4 & 18.2 & 18 & 81.8 & & \\
\hline Knowledge about contribution amount & No & 238 & 85.6 & 40 & 14.4 & 214.713 & $<0.001$ \\
\hline & Yes & 167 & 31.4 & 365 & 68.6 & & \\
\hline Having $\mathrm{HI}$ related books & No & 382 & 56.7 & 292 & 43.3 & 71.577 & $<0.001$ \\
\hline & Yes & 23 & 16.9 & 113 & 83.1 & & \\
\hline Participated in $\mathrm{HI}$ related training & No & 394 & 51.2 & 376 & 48.8 & 8.521 & 0.004 \\
\hline & Yes & 11 & 27.5 & 29 & 72.5 & & \\
\hline Interact with peers & No & 335 & 60.8 & 216 & 39.2 & 80.376 & $<0.001$ \\
\hline or neighbour about $\mathrm{HI}$ & Yes & 70 & 27.0 & 189 & 73.0 & & \\
\hline Known from social media & No & 336 & 51.3 & 319 & 48.7 & 2.306 & 0.129 \\
\hline & Yes & 69 & 44.5 & 86 & 55.5 & & \\
\hline Listened $\mathrm{HI}$ related information from Radio/FM & No & 259 & 61.1 & 165 & 38.9 & 43.731 & $<0.001$ \\
\hline & Yes & 146 & 37.8 & 240 & 62.2 & & \\
\hline Watched $\mathrm{HI}$ related information in TV & No & 290 & 58.0 & 210 & 42.0 & 33.445 & $<0.001$ \\
\hline & Yes & 115 & 37.1 & 195 & 62.9 & & \\
\hline Seen hoarding board & No & 335 & 56.4 & 259 & 43.6 & 36.465 & $<0.001$ \\
\hline & Yes & 70 & 32.4 & 146 & 67.6 & & \\
\hline
\end{tabular}




\begin{tabular}{llrrrrrr} 
Read newspaper & No & 367 & 52.1 & 337 & 47.9 & 9.769 & 0.002 \\
& Yes & 38 & 35.8 & 68 & 64.2 & & \\
\hline Seen brochure or poster or pamphlet & No & 359 & 53.7 & 309 & 46.3 & 21.348 & $<0.001$ \\
& Yes & 46 & 32.4 & 96 & 67.6 & & \\
\hline
\end{tabular}

Note: ${ }^{\wedge}=$ multiple responses

Sixty percent of the respondents, who had family member(s) having chronic disease(s), were enrolled in HI compared to 45 percent who had not $[p<0.001]$. Sixty-eight percent of the respondents who heard about HI were enrolled in HI compared to four percent who did not $[p<0.001]$. Eighty percent of the respondents, who got information from family members, were enrolled in $\mathrm{HI}$ compared to 79 percent from enrollment assistant, 76 percent from $\mathrm{FCHV}, 75$ percent from training or seminars, 74 percent equally from teachers and health workers/Doctors respectively, 69 percent from neighbours, 68 percent from Television, and 65 percent from Radio/FM [p<0.001]. Sixty-nine percent of the respondents, who had knowledge about contribution amount, were enrolled in $\mathrm{HI}$ compared to 14 percent who did not have knowledge regarding contribution amount $[\mathrm{p}<0.001]$. Eighty-three percent of the respondents, who had $\mathrm{HI}$ related books or guidelines, were enrolled in $\mathrm{HI}$ compared to 43 percent of those who had not $\mathrm{HI}$ related books or guidelines $[\mathrm{p}<0.001]$.

Similarly, 73 percent of the respondents, who participated in training or discussion of $\mathrm{HI}$ related programme, were enrolled in $\mathrm{HI}$ compared to nine percent of those who did not participate $[p<0.01]$. Seventy-three percent of the respondents, who discussed with peers or neighbours about $\mathrm{HI}$ related issues, were enrolled in $\mathrm{HI}$ compare to 39 percent of those who did not discuss [p<0.001]. Sixtytwo percent of the respondents, who listened $\mathrm{HI}$ related information from Radio/FM, were enrolled in $\mathrm{HI}$ compare 39 percent of those who did not listen [ $<0.001]$. Likewise, 63 percent of the respondents, who watched $\mathrm{HI}$ related message from Television, were enrolled in $\mathrm{HI}$ compare to 42 percent of those who did not watch [p<0.001]. Moreover, 68 percent of the respondents, who seen $\mathrm{HI}$ related message from Hoarding Board [HB], were enrolled in HI compare to 44 percent of those who did not see HB [p<0.001]. Sixty-four percent of the respondents, who read $\mathrm{HI}$ related message from newspaper, were enrolled in $\mathrm{HI}$ compared to 48 percent of those who did not read newspaper $[\mathrm{p}<0.01]$. Similarly, 68 percent of the respondents, who had seen $\mathrm{HI}$ related information from brochure, poster or pamphlet, were enrolled in $\mathrm{HI}$ compare to 46 percent of those who did not $[\mathrm{p}<0.001]$.

\section{Multivariate analyses of background characteristics; exposure to IEC; and enrollment in HI}

We used multivariate analysis in three models. In first model, we obtained background characteristics and enrollment in HI. In second model we presented exposure to communication and enrollment in HI. Lastly, in third model all these variables were included for further prediction.

According to Model I, it was found that higher the age higher the chances of enrollment. Respondents age 21 to 40 years, 41 to 60 years, and more than 60 years were 1.9 [aOR $=1.916$ ] times, 3.2 times [aOR $=3.200, p<0.05]$, and 4.4 times $[\mathrm{aOR}=4.352, \mathrm{p}<0.05] \mathrm{more}$ likely to enroll in $\mathrm{HI}$ respectively compared to age less than 21 years but not significant in Model III. Model I shows, the respondents who had family member(s) having chronic disease(s) were more likely to enroll in $\mathrm{HI}[\mathrm{aOR}=1.536, \mathrm{p}<0.01]$ compared to the family who had not chronic disease(s) within family member(s) but the result was not consistent in Model III.

The Model II shows the respondents who heard about health insurance were 20.5 times more likely to enroll compared to those who did not $[\mathrm{aOR}=20.521, \mathrm{p}<0.001]$. Similarly, the respondents who had knowledge about contribution amount for health insurance were 4.9 times more likely to enroll than those who did not have [aOR $=4.925, \mathrm{p}<0.001]$. Likewise, the respondents who had health insurance related books or guidelines were 5.1 times more likely to enroll in $\mathrm{HI}$ than those who had not [aOR $=5.117, p<0.001]$. Interestingly, the respondents who interact with peers or neighbours were 1.9 times more likely to enroll in $\mathrm{HI}$ compare to those who did not interact [aOR $=1.883, p<0.01]$.

Model III shows some similar and some contradictory projection compared to Model I and Model II. Age groups more than 20 years were more likely to enroll in $\mathrm{HI}$ compared to age upto 20 years which was the similar prediction with Model I. Model II and Model III have nearly the same result compared to Model I. The respondents who heard about HI were more likely to enroll in HI [aOR $=20.229$, $\mathrm{p}<0.001]$ compared to those who did not. The result seems similar to Model II. In the same way, the respondents, who had heard about $\mathrm{HI}$, knowledge on contribution amount, were more likely to enroll in $\mathrm{HI}[\mathrm{aOR}=5.176, \mathrm{p}<0.001]$ compared to those who had not. The respondents having $\mathrm{HI}$ related books or guidelines were more likely to enroll in $\mathrm{HI}[\mathrm{aOR}=4.812, \mathrm{p}<0.001]$ that was also the same result 
with Model II. The participants who had participated in the HI related training were less likely to enroll in $\mathrm{HI}$ compared to those who did not.

Interaction with peers and neighbours played positive role in enrollment. The respondents who interacted about HI with neighbours or peers were 1.7 times more likely to enroll in $\mathrm{HI}[\mathrm{aOR}=1.739, \mathrm{p}<0.01]$ compared to those who did not. The result was same to Model II. Multivariate analysis shows that Radio and or TV had no more influencing role in enrollment. Similarly, newspaper, poster, pamphlet, flayer or brochure had no positive and influencing role to the enrollment in HI. But The participants who saw HI related message from Hoarding Board were 1.3 times more likely to enroll in HI compared to those who did not.

Table 3: Logistic regression of background characteristics, and exposure to communication; and enrollment in HI

\begin{tabular}{|c|c|c|c|c|c|c|c|c|c|c|}
\hline \multirow{3}{*}{ Variables } & \multirow{3}{*}{ Attributes } & \multicolumn{3}{|c|}{ Model I } & \multicolumn{3}{|c|}{ Model II } & \multicolumn{3}{|c|}{ Model III } \\
\hline & & \multirow[b]{2}{*}{$\mathrm{aOR}$} & \multicolumn{2}{|c|}{$95 \% \mathrm{Cl}$} & \multirow[b]{2}{*}{$\mathrm{aOR}$} & \multicolumn{2}{|c|}{$95 \% \mathrm{Cl}$} & \multirow[b]{2}{*}{$\mathrm{aOR}$} & \multicolumn{2}{|c|}{$95 \% \mathrm{Cl}$} \\
\hline & & & Lower & Upper & & Lower & Upper & & Lower & Upper \\
\hline \multirow[t]{2}{*}{ Household head } & No (ref.) & & & & & & & & & \\
\hline & Yes & 1.075 & .776 & 1.487 & & & & .880 & .574 & 1.348 \\
\hline \multirow[t]{4}{*}{ Age group of respondents } & \multicolumn{4}{|c|}{ Upto 20 years (ref.) } & & & & & & \\
\hline & $\begin{array}{l}21 \text { to } 40 \\
\text { years }\end{array}$ & 1.916 & .727 & 5.052 & & & & 1.476 & .397 & 5.493 \\
\hline & $\begin{array}{l}41 \text { to } 60 \\
\text { years }\end{array}$ & $3.200 *$ & 1.158 & 8.843 & & & & 2.541 & .642 & 10.066 \\
\hline & $\begin{array}{c}\text { More than } \\
60 \text { years }\end{array}$ & $4.352^{\star}$ & 1.427 & 13.276 & & & & 3.774 & .838 & 16.995 \\
\hline \multirow[t]{3}{*}{ Wealth status } & Poor (ref.) & & & & & & & & & \\
\hline & Middle & .820 & .580 & 1.161 & & & & $.594 *$ & .364 & .969 \\
\hline & Rich & 1.204 & .849 & 1.707 & & & & .622 & .372 & 1.038 \\
\hline \multirow{2}{*}{$\begin{array}{l}\text { Family member having } \\
\text { chronic diseases }\end{array}$} & No (ref.) & & & & & & & & & \\
\hline & Yes & $1.536^{\star \star}$ & 1.129 & 2.089 & & & & .923 & .618 & 1.379 \\
\hline $\begin{array}{l}\text { Heard about health } \\
\text { insurance }\end{array}$ & $\begin{array}{l}\text { No (ref.) } \\
\text { Yes }\end{array}$ & & & & $20.521^{\star \star \star \star \star \star ~}$ & 10.020 & 42.025 & $20.229 * \star \star *$ & 9782 & 41.834 \\
\hline \multirow{2}{*}{$\begin{array}{l}\text { Knowledge about } \\
\text { contribution amount }\end{array}$} & No (ref.) & & & & & & & & & \\
\hline & Yes & & & & $4.925^{\star \star \star}$ & 3.049 & 7.953 & $5.176 * \star \star$ & 3.122 & 8.545 \\
\hline $\begin{array}{l}\text { Have } \mathrm{HI} \text { related books or } \\
\text { guidelines }\end{array}$ & $\begin{array}{l}\text { No (ref.) } \\
\text { Yes }\end{array}$ & & & & $5.117 \star \star \star *$ & 2.759 & 9.490 & $4.812^{\star \star \star}$ & 2.602 & 8.901 \\
\hline \multirow{2}{*}{$\begin{array}{l}\text { Participated in HI related } \\
\text { training }\end{array}$} & No (ref.) & & & & & & & & & \\
\hline & Yes & & & & .428 & .179 & 1.023 & .465 & .193 & 1.123 \\
\hline $\begin{array}{l}\text { Interact with peers and } \\
\text { neighbours about } \mathrm{HI}\end{array}$ & $\begin{array}{l}\text { No (ref.) } \\
\text { Yes }\end{array}$ & & & & $1.883^{* *}$ & 1.244 & 2.851 & $1.739 * \star$ & 1.141 & 2.650 \\
\hline $\begin{array}{l}\text { Listened } \mathrm{HI} \text { related info } \\
\text { from Radio/FM }\end{array}$ & $\begin{array}{l}\text { No (ref.) } \\
\text { Yes }\end{array}$ & & & & .917 & 611 & 1.375 & .919 & .609 & 1.387 \\
\hline \multirow{2}{*}{$\begin{array}{l}\text { Watched HI related } \\
\text { information in TV }\end{array}$} & No (ref.) & & & & & & & & & \\
\hline & Yes & & & & .831 & .551 & 1.255 & .934 & .604 & 1.444 \\
\hline Seen HI related & No (ref.) & & & & & & & & & \\
\hline hoarding board & Yes & & & & 1.342 & .827 & 2.178 & 1.413 & .865 & 2.308 \\
\hline \multirow{2}{*}{$\begin{array}{l}\text { Read HI related } \\
\text { newspaper }\end{array}$} & No (ref.) & & & & & & & & & \\
\hline & Yes & & & & .653 & .359 & 1.188 & .715 & .390 & 1.310 \\
\hline \multirow{2}{*}{$\begin{array}{l}\text { Seen HI related } \\
\text { brochure/poster/pamphlet }\end{array}$} & No (ref.) & & & & & & & & & \\
\hline & Yes & & & & .669 & .375 & 1.194 & .703 & .391 & 1.264 \\
\hline \multicolumn{2}{|c|}{$\begin{array}{c}\text { Consent } \\
-2 \text { Log likelihood }\end{array}$} & \multicolumn{3}{|c|}{$\begin{array}{c}.353^{\star} \\
1080.673\end{array}$} & \multicolumn{3}{|c|}{$\begin{array}{l}.022 * \star \star \\
713.426\end{array}$} & & $\begin{array}{l}017 * \star \star \\
99.222\end{array}$ & \\
\hline Cox \& Snell R Squa & & & .051 & & & 397 & & & .407 & \\
\hline
\end{tabular}

Note: *significant at $p<0.05, * *$ significant at $p<0.01, * * *$ significant at $p<0.001$

\section{Discussion}


IEC contains different approaches, activities and methods that targets to change the desirable behaviour thought the application of various activities by creating awareness, upgrading knowledge, changing desirable attitude, and supporting individuals for adopting an innovation or desirable behaviour (12,28-30). In this study, interaction and discussion with peers or neighbours seemed more productive for $\mathrm{HI}$ related communication. IEC materials were useful tool for promoting suitable eye awareness and also a powerful for social change in Madhurai, India (31). Similarly, it was observed that IEC and contraceptive uses were significantly associated beyond the visits of medical and family planning officers which was experienced in Indonesia (32). A study from Gambia shows that mass media was effective and feasible means to make change in maternal health service utilization and care (33). Similar observation seemed in India that IEC approaches appeared appropriate for consuming low salt diet to control hypertension (34) however flip chart seemed ineffective for food hygiene and food safety (35). IEC could be useful not only for making changes in behaviour but also for preparedness, response and mitigation for disaster that may save lives and resources (36).

Different audiences may be motivated from different mode of communication. Arroz (2017) states that Radio, dramas, lectures, posters and pamphlet, and folk programmes could considered as synergetic approaches but not replace one another (37). There was a significant difference between the respondents who listened $\mathrm{HI}$ message from radio and enrollment in $\mathrm{HI}$ compared to those who did not. The similar result was observed in Liberia that the women who listened radio spots were encouraged to care their child and visit health facilities of their babies appear with fever (38).

The study shows that educational level of respondents was not significantly associated with the enrollment but heard about $\mathrm{HI}$ was significantly associated with the enrollment in HI. A study from Nigeria shows that educational level of the participants was significantly associated with the awareness of national health insurance scheme (39). So it does not always mean that educational status is equal to $\mathrm{HI}$ literacy as well as enrollment. Another study from Columbia suggested that integrated approaches that are Radio, TV and interpersonal communication with health workers/volunteers were effective for seeking treatment for malaria (40). Consequently a study from Odisha, India shows that drugs adherence to IEC was significantly higher in receiving Artemisia in combination therapy in experiment group compared to control (41). Therefore, it can be concluded that IEC is an effective means to adopt an innovation or change in desired behaviour.

The study shows that nearly two third of the respondents, who interacted with peer or neighbours were enrolled compared to those who did not interact that was statistically significant. In the same way interaction with peers or neighbours was a positive significant predictor for enrollment in HI. Various empirical studies support the argument. Information and counselling from neighbours or peers make significant changes in behaviour modification. Not only a good behaviour but health destructive behaviours also influenced by peers (42). Peer teaching or coaching enhances relationship, reciprocal understanding, and development to achieve the targeted behaviour (43) besides these peer assessment improves students' learning outcomes with progressive attitudes (44). Not only that, the peering approach appears also successful in peer to peer fiscal planning and educational programmes (45).

The peer teaching method supports to develop in-depth and mutual understanding, cooperative and collaborative learning environment and also ensures self-assessment and monitoring of progress (46). Peering approach seems more effective specially for adolescents with high risk background. It connects with positive towards peer-to-peer relationship and they should be guided in supporting oneanother in promoting healthy behaviour (47). The approach has been recognized as an effective and valuable approach so can be incorporated into different setting using various methods and approaches (48) which might be fastest, cheapest, efficient, and beneficial approach and can be utilized social as well as cognitive field (49).

The peering or neighbouring approach leads productive social interaction, responsiveness, co-operation and positive attitudes and social harmony. It supports learning environment and encouraging participation in interaction (50). A systematic review shows that adolescents and sexuality health education had improved in knowledge, attitude and intentions by peer leading approach (51). Peer mediated approach also leads to positive changes in social behaviour of person having learning disabilities (52). Another experimental study shows that peer education significantly increased knowledge and practice of mental health of adolescents girls (53).

Peers/neighbours support in three different ways: first, social; second, informational; and lastly, personal or folk, facts and feelings respectively which are interconnected with interpersonal skills. From the biomedical point of view on breastfeeding, peer to peer [P2P] approach is women centred, related to their own experiences, considering women as change agent from their own experiences and able to cope cultural constrains therefore recommended for P2P approach (54). From the result of this study and empirical evidences from other studies show that P2P or neighbouring approach is more convenient, efficient and effective way to change or modification of the behaviour. 


\section{Limitation}

The study was conducted in Baglung and Kailali Districts since the HIP was initially implemented in these districts. Households enrolled after $15^{\text {th }}$ January, 2018 and enrolled from other organization/company except HIB were excluded. For the non-enrolled sample, the proximal household to enrolled was selected assuming that they [both enrolled and non-enrolled household] may have equal access to mass media and communication. The study period was 75 days started from March $20^{\text {th }} 2018$ and it captures information given by the respondents on that particular period. The article has mainly focused on IEC activities with reference to sociodemographic characteristics.

\section{Conclusion}

From the data of the study and empirical evidences from other studies, it can be concluded that heard about $\mathrm{HI}$ and knowledge about contribution amount seem major predictors for enrolment. Similarly, HI related books, guidelines and Hoarding Board can support for mass participation. The existing ways of message dissemination through Radio, TV, newspaper, poster and pamphlet seem less effective for enrolment. It would be better to be re-evaluated for disseminating message to public awareness or it could be modified for betterment. But, interaction with peer or neighbour seemed a positive and significant predictor for enrollment in HI. Therefore, policy maker should think of these facts while planning for the interventions.

\section{List Of Abbreviations}

aOR: Adjusted Odds Ratio

CoN:Constitution of Nepal

GoN:Government of Nepal

HH:Household Head

HI:Health Insurance

HIA:Health Insurance Act

HIB:Health Insurance Board

HIP:Health Insurance Programme

IEC:Information, education, and Communication

IS:Interview Schedule

NDHS: Nepal Demographic and Health Survey

NHRC: Nepal Health Research Council

SDGs:Sustainable Development Goals

SHS:Social Health Security

SPSS:Statistical Package for Social Sciences

UHC:Universal Health Coverage

\section{Declarations}

\section{Ethical Approval and consent to participate}

NHRC reviewed and approved the study proposal. Consent was taken prior to interview.

Page 12/16 


\section{Consent for Publication}

Not applicable.

\section{Availability of data and materials}

The datasets used and/or analysed during the current study are available from the correspondence author on reasonable request.

\section{Competing interest}

The authors declare that they have no competing interest.

\section{Funding}

Since the article is a part of PhD, partial support [as PhD Fellowship] was received from University Grants Commission [UGC], Nepal, but UGC had no influence all over process of study/research [PhD Fellowship Award HERP: 2072/73, Edu-01].

\section{Authors' contribution}

DA, the principal author of this paper, designed, analysed and interpreted the data. BD supervised all over process of study and reviewed, edited the manuscript. KG involved in manuscript drafting and made correction on it. RB involved in data collection, data entry. All authors read and approved in final version of the manuscript.

\section{Acknowledgments}

The authors would like to thank University Grants Commission, Nepal and anonymous reviewers of this paper.

\section{Authors' information}

DA, PhD Scholar: Faculty of Education, Tribhuvan University, Nepal. BD, PhD: Professor, Mahendra Ratna Campus, TU, Kathmandu. KG, PhD: Associate Professor, Central Department of Education, TU, Kirtipur, Kathmandu. RB, M Ed: Teaching Assistant, Bhairahawa Multiple Campus, TU, Bhairahawa, Nepal

\section{References}

1. Government of Nepal National Planning Commission. Sustainable Development Goals 2016-2030: National \{Prelinimary\} Report [Internet]. Singha Durbar, Kathmandu, Nepal; 2015. Available from: https://www.undp.org/content/dam/nepal/docs/reports/SDG final report-nepal.pdf

2. Nepal Law Commission. Constitution of Nepal 2015 [Internet]. Member of Parliament. Nepal; 2015. Available from: http://www.lawcommission.gov.np/en/documents/2016/01/10272.pdf

3. Department of Health Services. Annual Report: Department of Health Services 2074/75 (2017/18) [Internet]. Kathmandu; 2019. Available from: https://dohs.gov.np/wp-content/uploads/2019/07/Annual_Report_2074-751.pdf

4. Member of Parliament Nepal. Health Insurance Act, 2074 [Internet]. Nepal: Member of Parliament. Nepal; 2017 p. 1-18. Available from: http://www.lawcommission.gov.np/np/archives/24220

5. Health Insurance Board. Annual Report FY 2073/74(2016/17) [Internet]. Kathmandu; 2017. Available from: http://shs.gov.np/site/content/detail/annual-report-of-fy-2073074

6. KOICA-Nepal Health Insurance Support Project [NHISP]. Comprehensive district assessment for health insurance in Kailali district. Lalitpur, Kathmandu; 2014.

7. KOICA/HIMAL Project. Community-based health insurance: Implementation manual. Sanepa, Lalitpur; 2012.

Page 13/16 
8. Ghimire R. Community based health insurance practices in Nepal [Internet]. Academia. 2012 [cited 2019 Mar 4]. p. 1-11. Available from: https://www.academia.edu/5587577/Community_Based_Health_Insurance_Practices_in_Nepal

9. Social Security Health Development Committee. Communication strategy on social health security in Nepal. Kathmandu; 2015.

10. Mefalopulos P. Development communication sourcebook: Brodening the biundaries of communication. Washington, D.C.: The International Bank for Reconstruction and Development/The World Bank; 2008.

11. Mundorf N, Redding CA, Paiva AL. Sustainable transportation attitudes and health behavior change: Evaluation of a brief stagetargeted video intervention. Int J Environ Res Public Health. 2018;15(1).

12. World Health Organization. Information, education, and communication: Lessons from the past; perspectives for the future [Internet]. World Health Organization. Geneva; 2001. Available from: http://books.google.com $/$ books?hl = en\&lr $=\& i d=$ 0xBlkjNvYSAC\&oi $=$ fnd\&pg $=$ PA285\&dq $=$ information,, education+and + communication\&ots $=$ shN5gsrngU\&sig $=$ 3rAIRSZbyAJtFI1HFOzkmUxOqXI

13. Zimbabwe National Family Planning Council. IEC reference manual for health programme managers. Harare: Zimbabwe National Family Planning Council; 1998. 5 p.

14. Piotrow PT, Kincaid DL, Rimon JGI, Rinehart W. Health communication: Lessons from family planning and reproductive health. Westport, CT: Praeger Publishers; 1997.

15. Ministry of Health; New ERA; \& ICF. Nepal Demographic and Health Survey 2016 [Internet]. Kathmandu, Nepal: Ministry of Health, Nepal; 2017. Available from: www.dhsprogram.com/pubs/pdf/fr336/fr336.pdf

16. Water Aid. Behaviour Change Theory -Outline [Module I] [Internet]. p. 1-12. Available from: https://www.Ishtm.ac.uk/media/11191

17. Barker K. Order from chaos: Organizational aspects of information, education, and communication (a case study from Mali). J Health Commun [Internet]. 2003;8(4):383-94. Available from: https://doi.org/10.1080/10810730305726

18. Iordache-Platis M, Josan I. Communication efficiency within higher education institutions: The case of Romania. Eur Res Stud. 2009;12(4):55-66.

19. Puri S. The role of information, education and communication (IEC) in sustainable solid waste management. Open Access Int $J$ Sci Eng. 2017;2(9):102-6.

20. Ubiquitous Information Society Advisory Board. National plan for educational use of information and communications technology. 2010.

21. Sample size calculator [Internet]. SurveyMonkey. 2019. Available from: https://www.surveymonkey.com/mp/sample-sizecalculator/

22. Central Bureau of Statistics. Statistical Pocket Book of Nepal. Kathmandu; 2014.

23. Acharya D, Devkota B, Wagle BP. Factors associated to the enrollment in health insurance: An experience from selected districts of Nepal. Asian Soc Sci [Internet]. 2019;15(2):90-9. Available from: https://doi.org/10.5539/ass.v15n2p

24. Naing L, Winn T, Rusli BN. Practical issues in calculating the sample size for prevalence studies. Arch Orofac Sci. 2006;1(Ci):9-14.

25. Nepal Health Research Council. National ethical guidelines for health research in Nepal and standard operating procedures. Ramshah Path, Kathmandu: Nepal Health Research Council; 2011. 1-40 p.

26. American Psychological Association. Publication manual of the American Psychological Association. 6th ed. Washington, DC: American Psychological Association; 2010. 1-272 p.

27. Central Bureau of Statistics. Statistical pocket book of Nepal 2014 [Internet]. Kathmandu: Government of Nepal, National Planning Commission Secretariat, Central Bureau of Statistics; 2015. Available from: https://cbs.gov.np/wpcontent/upLoads/2019/02/Statistical-Pocket-Book-2014.pdf

28. Akhund S, Avan BI. Development and pretesting of an information, education and communication ( IEC) focused antenatal care handbook in Pakistan. BMC Res Notes. 2011;4(91).

29. World Health Organization. WHO/UNICEF regional workshop on information, education and communication on health. Manila; 1981.

30. World Health Organization. Information, education and communication: A guide for AIDS programme managers. New Delhi; 2000.

31. Abraham PG, Sheeladevi S. The need and process of IEC (Information, Education and Communication) development in delivering paediatric eye care services [Internet]. India, Madurai.; Available from: http://v2020eresource.org/content/files/IEC_article.pdf 
32. Winarni E, Dawam M. Family planning information, education and communication with contraceptive use. Natl Public Heal J. 2016;11(2):94-102.

33. Anya SE, Hydara A, Jaiteh LES. Antenatal care in The Gambia: Missed opportunity for information, education and communication. BMC Pregnancy Childbirth. 2008;8(9):1-7.

34. Borah PK, Kalita HC, Paine SK, Khaund P, Bhattacharjee C, Hazarika D, et al. An information, education and communication module to reduce dietary salt intake and blood pressure among tea garden workers of Assam. Indian Heart J [Internet]. 2018;70(2):252-8. Available from: http://dx.doi.org/10.1016/j.ihj.2017.08.008

35. Takanashi K, Quyen DT, Hoa NT Le, Khan NC, Yasuoka J, Jimba M. Long-term impact of community-based information, education and communication activities on food hygiene and food safety behaviors in Vietnam: A longitudinal study. PLoS One. 2013;8(8).

36. Crane O, Balen J, Devkota B, Ghimire S, Rushton S. Use of information and communication technologies in the formal and informal health system responses to the 2015 Nepal earthquakes. Health Policy Plan. 2017;32:48-58.

37. Arroz JAH. Social and behavior change communication in the fight against malaria in Mozambique. Rev Saude Publica [Internet]. 2017;51(0):1-5. Available from: http://www.scielo.br/scielo.php?script = sci_arttext\&pid = S0034-89102017000100603\&lng = en\&tlng $=$ en

38. Awantang G, Babalola S, Koenker H, Fox K, Toso M, Lewicky N, et al. Correlates of social behavior change communication on care - seeking behaviors for children with fever: an analysis of malaria household survey data from Liberia. Malar J [Internet]. 2018;17:1-10. Available from: https://doi.org/10.1186/s12936-018-2249-x

39. Adewole DA, Akanbi SA, Osungbade KO, Bello S. Expanding health insurance scheme in the informal sector in Nigeria: awareness as a potential demand-side tool. Pan Afr Med J. 2017;27(52):1-11.

40. Canavati SE, Beyl CZ De, Ly P, Shafique M, Boukheng T, Rang C, et al. Evaluation of intensified behaviour change communication strategies in an artemisinin resistance setting. Malar J. 2016;15(249):1-13.

41. Swain TR, Raulo A, Mohapatra N, Singha MR. Information Education and Communication can Improve Adherence to ArtemetherLumefantrine Combination in Patients of Uncomplicated Falciparum Malaria. J Clin Diagn Res [Internet]. 2015;9(9):FC01-3. Available from: http://www.ncbi.nlm.nih.gov/pubmed/26500920\%5Cnhttp://www.pubmedcentral.nih.gov/articlerender.fcgi?artid = PMC4606249

42. Vries $\mathrm{H}$ de, Candel M, Engels R, Mercken L. Challenges to the peer influence paradigm: results for 12-13 year olds from six European countries from the European Smoking Prevention Framework Approach study. Tob Control. 2006;15:83-9.

43. Parker P, Wasserman I, Kram KE, Hall DT. A relational communication approach to peer coaching. J Appl Behav Sci. 2015;51(2):231-52.

44. Friedman BA, Cox PL, Maher LE. An expectancy theory motivation approach to peer assessment. J Manag Educ. 2008;32(5):580612.

45. Goetz JW, Durband DB, Halley R, Davis K. A peer-based financial planning and education service program: An innovative pedagogic approach a peer-based financial planning. J Coll Teach Learn. 2011;8(4):7-14.

46. Ramaswamy S, Harris I, Tschirner U. Student peer teaching: An innovative approach to instruction in science and engineering education. J Sci Educ Technol. 2001;10(2):165-6.

47. Eggert LL, Nicholas LJ, Owen LM. Reconnecting youth: A peer group approach to building life skills. Bloomington, Indiana: Naional Education Service; 1995.

48. Evans DJR, Cuffe T. Near-peer teaching in anatomy: An approach for deeper learning. Anat Sci Educ. 2009;2(October):227-33.

49. Coenen ME. Using gifted students as peer tutors: An effective and beneficial approach. Winter. 2002;25(1):48-55.

50. Hwang G, Chang S. Effects of a peer competition-based mobile learning approach on students' affective domain exhibition in social studies courses. Br J Educ Technol. 2016;47(6):1217-31.

51. Ranabhat CL, Kim C, Singh A, Acharya D, Pathak K. Challenges and opportunities towards the road of universal health coverage ( UHC) in Nepal: a systematic review. Arch Public Heal [Internet]. 2019;77(5):1-10. Available from:

https://doi.org/10.1186/s13690-019-0331-7\%0A(2019)

52. Moore T, Carey L. Friendship formation in adults with learning disabilities: Peer- mediated approaches to social skills development. Br J Learn Disabil. 2005;33:23-6.

53. Taghdist MH, Noori SM, Merghati KE, Hoseini F, Asgharnejad FAA. Impact peer education approach on knowledge and practice about mental health of adolescent girls. Toloo-E-Behdasht. 2012;10(3-4(33)):92-105.

Page 15/16 
54. Smale M. Training breastfeeding peer supporters: An enabling approach. Blackwell Publishing Ltd (Maternal and Child Nurition); 2005. p. 59-60. 